\title{
Synthesis of Hydrophilic Polyelectrolyte as Draw Solute for Forward Osmosis Process
}

\author{
W. Khongnakorn*, W. Bootluck \\ Membrane Science and Technology Research Center (MSTRC), Department of Civil \\ Engineering, Faculty of Engineering, Prince of Songkla University, Songkhla, 90112, \\ Thailand
}

\begin{abstract}
Synthesis and characterization of hydrophilic polyelectrolyte was performed in this work and used as draw solute for forward osmosis (FO) process. The effect of different ratios of acrylic acid (AA) and benzoyl peroxide (B) on the properties of polyelectrolyte was studied in this work. The physical and chemical properties of draw solution (DS) such as $\mathrm{pH}$, conductivity, osmolality, viscosity, molecular weights and functional group were investigated. Results showed that the solution osmolality increased with increasing AA/B ratio. Self-synthesized polyelectrolytes with different molecular weights (MWs) were further correlated with its solution osmolality. The self-synthesized polyelectrolytes of PAA-K and PAA-Na showed an increasing of hydrophilic functional groups such as $-\mathrm{OH}$ or $\mathrm{COOH}$. PAA-Na with lower MW and high osmotic pressure in the aqueous solution is found to exhibit a lower reverse solute flux during FO process. Meanwhile for the polyelectrolyte with higher MW, higher viscosity and lower diffusion coefficient were reported.
\end{abstract}

Keywords: Forward osmosis, draw solution, polyelectrolyte, reverse solute flux, diffusion

\subsection{INTRODUCTION}

Forward osmosis (FO) is one of the membrane separations technology for water reuse and desalination. The FO has naturally driven force use osmotic pressure difference across a semipermeable membrane process [1-4]. Compare FO processes to hydraulic pressure process is more advantage such as low energy consumption and low membrane fouling [5]. There are three components in the FO system. Firstly, the membrane type is important to fabric and modify the high hydrophilic membrane [1]. Secondly, draw solution (DS) is a solution with high osmotic pressure. Finally, the recovery method of DS is the process to maintain a constant concentration of DS, which is commonly used by a membrane separation process such as Nanofiltration, ultrafiltrationn membrane distillation, etc [6-8]. Several solutions have been used for DS for instance $\mathrm{NaCl}, \mathrm{MgCl}_{2}, \mathrm{KNO}_{3}$, $\mathrm{MgSO}_{4}$, sucrose, ammonium bicarbonate $\left(\mathrm{NH}_{4} \mathrm{HCO}_{3}\right)$ ammonium hydroxide $\left(\mathrm{NH}_{4} \mathrm{OH}\right)$. Lutchmiah et al. [8] reported that $\mathrm{NaCl}$ is a favored solution used for DS amount $40 \%$. The criteria to consider the selection of the DS by Achilli et al. [9] is high water solubility, high flux obtain, high osmolality, lower salt leakage, low energy for recovery and stability after recovery.

Researchers have investigated the use of inorganic salts as draw solutions due to low cost and high osmotic pressure potential, which creates a high water flux. Hydrophilic magnetic nanoparticle (MNP) has been used as a 
draw solution with high osmotic and high water flux and easy to recycle of draw solute $[4,6]$ In addition, other materials have been used for FO. Ge et al. [4] have studied the different molecular weights of the sodium salt of polyacrylic acid (PAA-Na). It presented the solute with the lowest molecular weight that obtained the maximum FO flux due to its low viscosity and high dissociation. Nguyen et al. [10] studied FO process with $0.1 \mathrm{M}$ EDTA-2Na coupled with $15 \mathrm{mM} \mathrm{NP7}$ as a draw solution. The results showed that the lowest reverse salt flux was observed due to the hydrophobic interaction between the tails of NP7 and the FO membrane. Kumar et al. [11] synthesized the hydrolyzed poly (isobutylene-altmaleic acid) (PIAM-Na) and used as draw solute for $\mathrm{FO}$ desalination. Huang et al. [12] employed P(SSA-co$\mathrm{MA}$ )-Na as a novel draw solute in FO process and showed high water flux. Nevertheless, the main problem of draw solutions show reasonable water flux but high reverse salt flux (RSF) $[10,12]$. Salt leakage is occurred by the accumulation of concentration or internal concentration polarization (ICP). That is based on the diffusionconvection transport of draw solution in the support layer [3]. The objective of this work is to synthesize new type of polyelectrolyte and use it as draw solute for FO process. It is expected that the draw solution could achieve high osmotic pressure and high water flux without minimum low reverse salt leakage.

\subsection{METHODS}

\subsection{Materials}

Acrylic acid (AAc, purity 99\%, 200 ppm monomethyl ether hydroquinone as inhibitor) was obtained from LobaChemie, Mumbai, India. Ethanol (purity $99.99 \%$ ) was purchased from RCI lab scan Limited, Thailand. Benzoyl Peroxide (98\%, humidified with $25 \%$ of $\mathrm{H}_{2} \mathrm{O}$ PS) was acquired from Panreac Quimica S.L.U., Spain. Sodium hydroxide $(\mathrm{NaOH}$, purity 99\%) was purchased from Merck, Germany. Potassium hydroxide $(\mathrm{KOH}$, purity $85 \%$ ) was achieved from Ajax Finechem, Australia. Acetone (purity $99.5 \%$ ), Surfactant (Triton ${ }^{\mathrm{TM}} \mathrm{X}-114$ ) and PAA-Na (1200) were purchased from Sigma-Aldrich, UK. Membrane TFC was supplied from HTI (Hydration Technologies Inc., OR, USA).

\subsection{Preparation of PAA}

AAc $15 \mathrm{ml}$ and acetone $150 \mathrm{ml}$ were mixed at $110^{\circ} \mathrm{C}$, before adding $10 \mathrm{~g}$ of benzoyl peroxide and stirred well for $90 \mathrm{~min}$. The final PAA mixture was dried in vacuum at $100{ }^{\circ} \mathrm{C}$ for $30 \mathrm{~min}$. The reaction of synthesis polymerization of acrylic acid was shown in Figure 1.

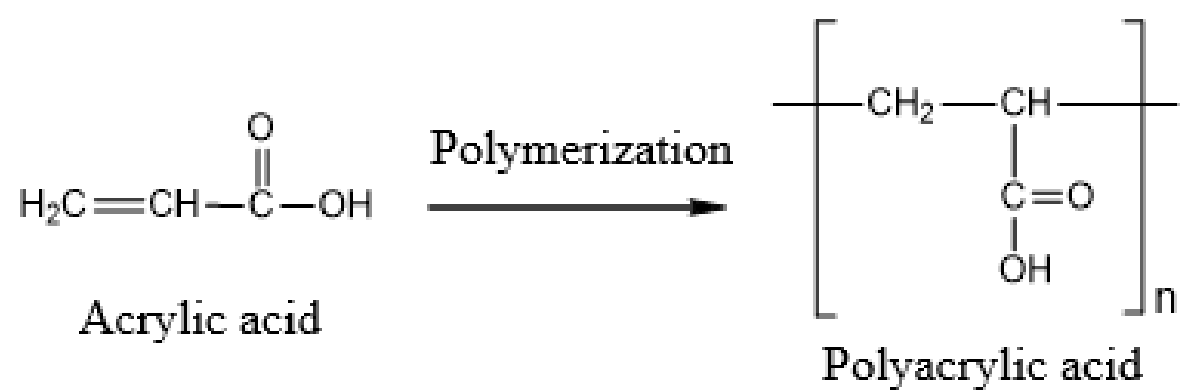

Figure 1 The reaction of polymerization of polyacrylic acid 
2.3 Synthesis of PAA-K and PAA$\mathrm{Na}$

The preparation of PAA-K was taken PAA amount $10 \mathrm{~g}$ (From 2.2) and was mixed with $3.5 \mathrm{~g}$ of $\mathrm{KOH}$ then dissolved in $100 \mathrm{ml}$ of ethanol. Surfactant (Triton $\left.^{\mathrm{TM}} \mathrm{X}-114\right) \quad 0.026$ $\% \mathrm{w} / \mathrm{v}$ was added and stirred well mixing for $30 \mathrm{~min}$ at room temperature. The final product of
PAA-K was obtained after filtrated and dried in the vacuum oven. For the preparation of PAA-Na, was also prepared using the same procedure except $\mathrm{NaOH}$ used instead of $\mathrm{KOH}$. The initial concentration of each polyelectrolyte for the characterization was used at 0.48 g.mL $\mathrm{m}^{-1}$ [7]. The reaction of synthesis of the polyelectrolytes salt is shown in Figure 2.

\section{PAA-K}

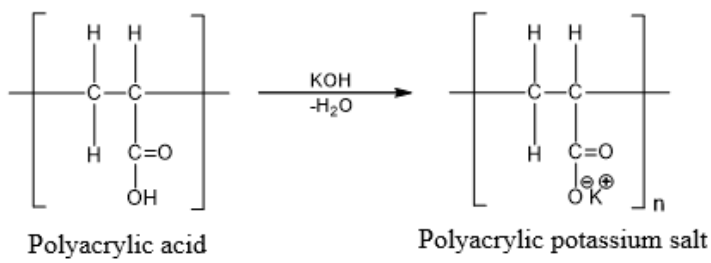

PAA-Na

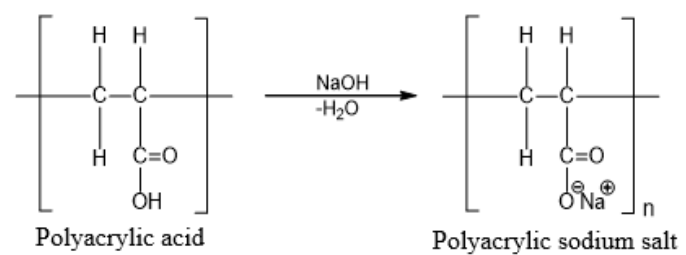

Figure 2 The reaction of synthesis of the polyelectrolytes; PAA-K and PAA-Na

\subsection{Characterization of PAA}

The characterization of PAA, the chemical functional group was analyzed by Attenuated Total Reflectance- Fourier transform Infrared spectroscopy, ATR-FTIR (Tensor 27, Bruker, US). The $\mathrm{pH}$ was tested by $\mathrm{pH}$ meter (Cyberscan Pc 300, Eutech instruments). Conductivity was measured by conductivity meter (WTW, LF318, Germany). The osmolality was measured by Osmometer (Fiske Associates 210, Massachusetts, USA). The viscosity of PAA-Na and PAA-K were measured by viscometer (Brookfield, USA). The molecular weight of self-synthesized polyelectrolytes analyzed by Liquid Chromatography Mass Spectrometer
(LCMS, Q-TOF 6545 Agilent Technologies, USA).

\subsection{Membrane Permeability and DS Testing in FO Process}

A lab-scale FO system was employed for all FO tests. The commercial thin film composite (TFC) FO membrane from HTI (Hydration Technologies Inc., OR, USA) was used in this work. The FO module was made from Acrylic plastic with $15 \mathrm{~cm}$. length, 5 $\mathrm{cm}$. width, and $0.3 \mathrm{~cm}$. depth for each side. $\mathrm{NaCl}, \mathrm{PAA}-\mathrm{Na}$ and PAA-K were used as the draw solutions and DI water was used as the feed solution. During the FO test, both feed and draw solutions operated at a fixed volumetric flow rate $(100 \mathrm{ml} / \mathrm{min})$ at 
room temperature $\left(25 \pm 1{ }^{\circ} \mathrm{C}\right)$ in cocurrent mode. Ultrafiltration was used for the recovery process. For UF experiments, polyvinylidene difluoride (PVDF) hollow fiber membrane (Steritech, USA) of $0.05 \mathrm{~mm}$ pore size was operated under pressure of 5 bars. The schematic of laboratory scale is presented in Figure 3. The water flux $\left(J w, \mathrm{~L} / \mathrm{m}^{2} \cdot \mathrm{h}\right.$, referenced to as $\left.\mathrm{LMH}\right)$ was measured from the weight of permeate and calculated following $E q$. (1).

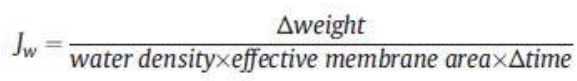

The reverse solute flux, RSF ( $J S$, $\mathrm{g} / \mathrm{m}^{2} \cdot \mathrm{h}$, referenced to as $\mathrm{gMH}$ ) was measured based on the calibration curve of the conductivity versus the polyelectrolytes salt concentration. The RSF was determined using Eq. (2).

$J s=\frac{\Delta C t V t}{A \Delta t}$

where $C t(\mathrm{~g} / \mathrm{L})$ and $V t(\mathrm{~L})$ are the reverse solute concentration and the volume of the feed solution, respectively, at an arbitrary time $t$ [11]. Number of recovery cycle were determined for water flux $(J, \mathrm{LMH})$ production after filtrated by ultrafiltration.

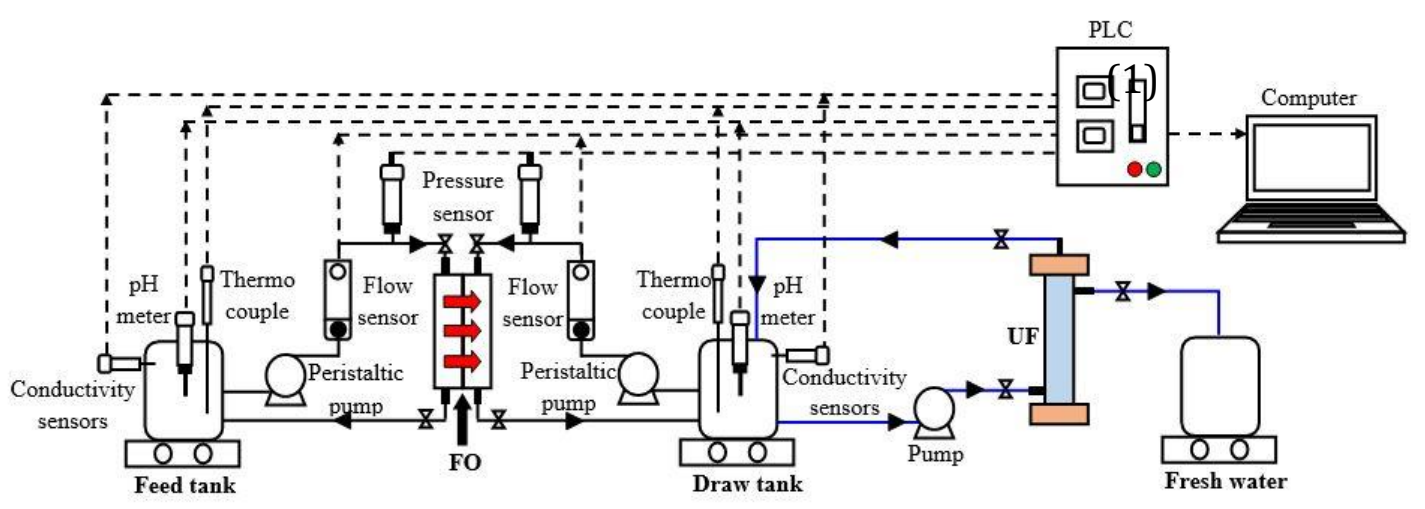

Figure 3 The schematic of laboratory scale

\subsection{RESULTS AND DISCUSSION}

\subsection{Characterization}

\subsubsection{Functional Group of PAA, $P A A-K$ and $P A A-N a$}

FTIR-ATR spectrum of synthetic polyelectrolytes (Figure 4) showed the strong peak at wavenumber $3,422 \mathrm{~cm}^{-1}$ and $3,428 \mathrm{~cm}^{-1}$ (O-H stretching) of hydroxyl group for PAA-K and PAA-
$\mathrm{Na}$, respectively. The FTIR spectra showed the increasing of hydrophilic functional group such as $-\mathrm{OH}$ group, formed after the polymerization of polyelectrolytes. In addition for PAA$\mathrm{Na}$, showed the shoulder peaks of $\mathrm{C}=\mathrm{C}$ and $\mathrm{C}=\mathrm{O}$ attributed to carboxylic acid groups. These results are similar to Kumar et al. [11] that demonstrated these peaks after the hydrolysis of anhydride. 


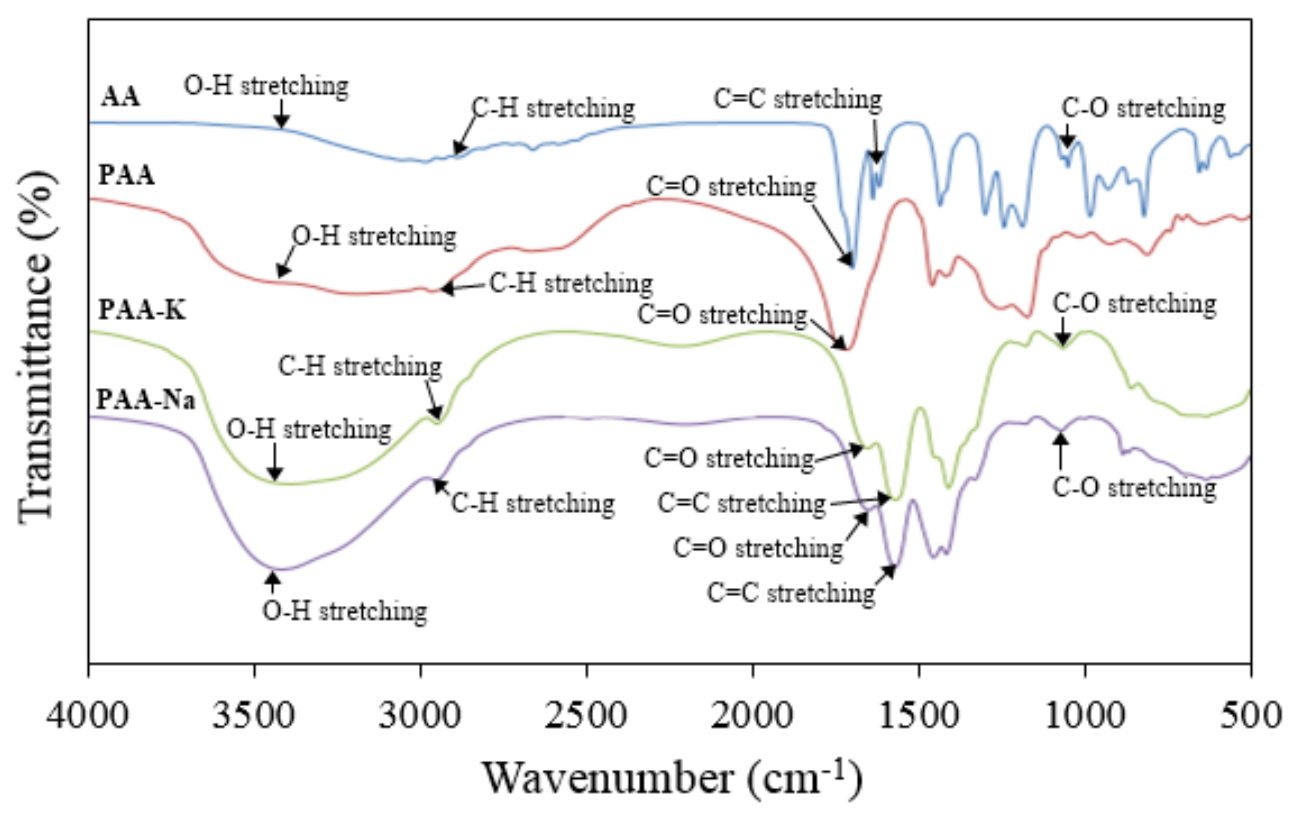

Figure 4 ATR-FTIR spectra of; PAA, PAA-K, PAA-Na

3.1.2 pH of PAA, PAA-K and PAA$\mathrm{Na}$

$\mathrm{pH}$ value of self-synthesized polyelectrolytes (Figure 5), they were 2.6 (acidity), 9.3 (alkalinity) and 7.1 (neutral) for PAA, PAA-K and PAA$\mathrm{Na}$, respectively. The self-synthesized polyelectrolytes of PAA-Na showed neutral $\mathrm{pH}$ that similar to the commercial PAA-Na is equal to 7.1.
These results presented that selfsynthesized PAA-Na is suitable to use in the FO process. The FO membrane such as cellulose triacetate membrane (CTA) and thin film composite membrane (TFC) are famous comercial membrane use for the system and operate in the neutral $\mathrm{pH}$ values [9].

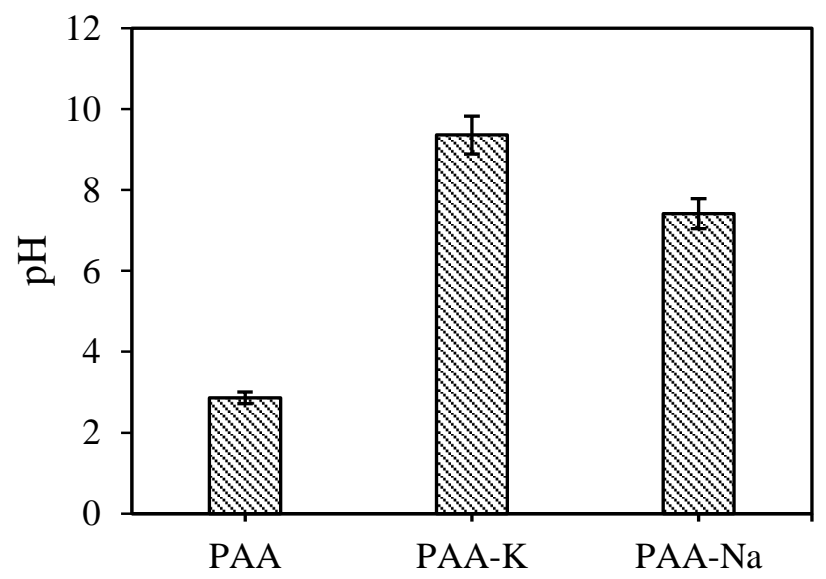

Figure 5 The pH of PAA, PAA-K, PAA-Na 
3.1.3 Conductivity of PAA, PAA-K and PAA-Na

Figure 6 presents the conductivity of self-synthesized polyelectrolytes as draw solution in FO process. These were found that the conductivity were increased after salt co-polymerization.
PAA-Na showed the highest conductivity at $6.54 \mathrm{mS} / \mathrm{cm}$ while as the commercial presented at 5.3 $\mathrm{mS} / \mathrm{cm}$. These results are less than obtained by Huang et al. [12] at 47.5 $\mathrm{mS} / \mathrm{cm}$. These are difference value due to the initial moles are difference in mass concentration.

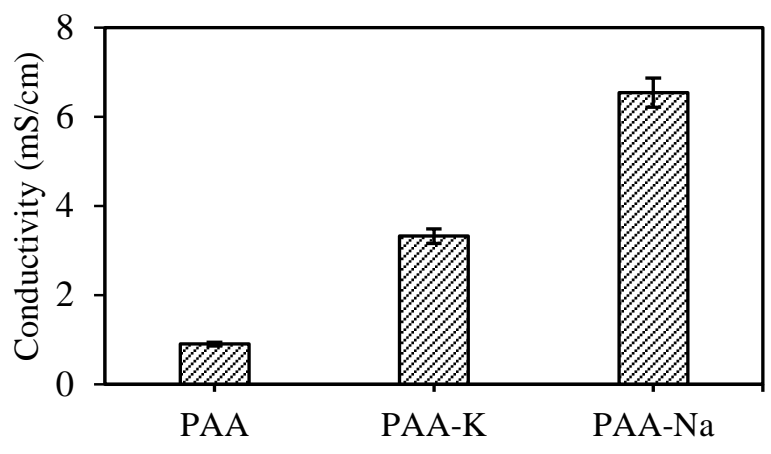

Figure 6 Conductivity of PAA, PAA-K, PAA-Na

\subsubsection{Viscosity of PAA, PAA-K and PAA-Na}

The viscosity of self-synthesized polyelectrolytes is presented in Figure 7. The viscosity increased from 21.48 $257.79226 .28 \mathrm{mPa} / \mathrm{s}$ for PAA, PAA-K and PAA-Na, respectively. The viscosity of PAA-K shown higher with a larger of MW of draw solution. The viscosity of commercial PAA-Na is 0.1 $\mathrm{mPa} / \mathrm{s}$. It is higher solubility than the self-synthesized PAA-Na. However, the higher of viscosity is the main problem in the FO process that decreased flux [12]. Nguyen et al. [10] said the hydrophobic of tail of surfactant show the reaction at the membrane surface that low RSF. These confirmed that behaviors because of the viscosity of self-synthesized polyelectrolytes is too high but less of RSF (in section 3.2.1).

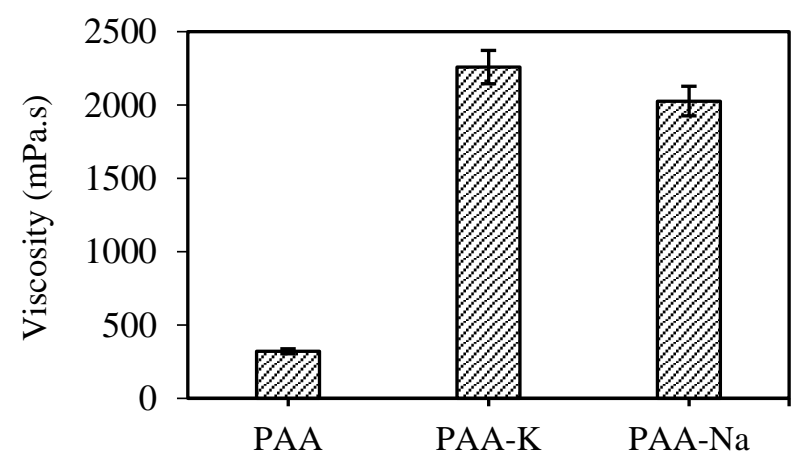

Figure 7 The viscosity of PAA, PAA-K, PAA-Na 


\subsubsection{Molecular Weight of PAA Salts and Their Osmolality}

As the result, PAA salts in term of PAA-NA was lower molecular weight than PAA-K and PAA, respectively. In addition, it showed highest osmolality in this study (Figure 8). Table 1 presents the molecular weight of the PAA salts, the self-synthesized PAA-
$\mathrm{Na}$ is close to the commercial PAA-Na (MW1200). In comparison, selfsynthesized polyelectrolytes is high osmotic pressure than the commercial PAA-Na. This results might be explained by the different concentration of the free counter ion in the solution from the synthesized process [11].

Table 1 The molecular weight of polyelectrolytes

\begin{tabular}{lcc}
\hline Condition & $\mathbf{m} / \mathbf{z}$ & $\begin{array}{c}\text { Molecular } \\
(\mathbf{g} / \mathbf{m o l})\end{array}$ \\
\hline PAA & 1,904 & 1,903 \\
PAA-K & 3,478 & 3,477 \\
PAA-Na* & 1,268 & 1,267 \\
PAA-Na** & 1,200 & 1,200 \\
\hline * Self-synthesized PAA-Na & \\
** Commercial PAA-Na &
\end{tabular}

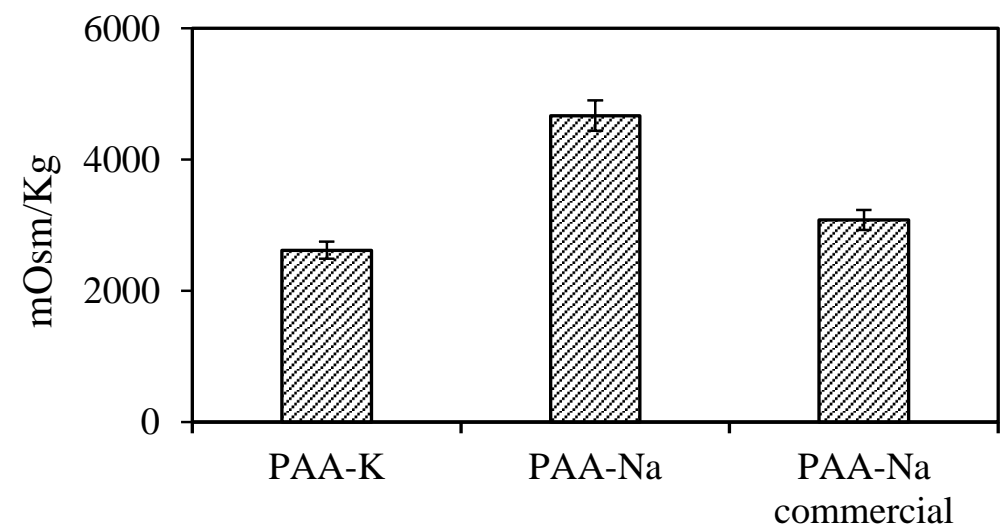

Figure 8 The osmolality of PAA-K, PAA-Na and Commercial PAA-Na

\subsection{FO performances}

\subsubsection{Water Permeation Flux and Reverse Solute Flux}

The application of the self-synthesized PAA-Na and commercial PAA-Na as the draw solute in the FO system were evaluated by measuring the water permeation flux and reverse solute flux (RSF) values as shown in Figure 9. The water flux of the self-synthesized PAA-Na was higher than commercial PAA-Na due to their chemical characteristics are difference especially the osmotic pressure. The osmorlity is the key parameters for the flux obtained. In addition, the molecular weight of polymer chains in the solution and the initial concentration are effect on the osmolarity. The RSF of both polyelectrolytes found that similar value at 0.023 and $0.024 \mathrm{gMH}$ for self-synthesized PAA-Na and commercial PAA-Na, respectively. These result could be explained by the effect of the adding the surfactant that present hydrophobic interaction effect. 
The hydrophobic tail of the surfactant interacts with the hydrophobic membrane and trapped the membrane pores, leading to a significant reduction in the reverse salt diffusion of $\mathrm{Na}^{+}$[10]. In addition, compared with the control by the $\mathrm{NaCl}$ was also investigated. The osmotic pressure of $\mathrm{NaCl}$ was high, but the salt conversion was also high.
Considering only the RSF, it was found that self-synthesized PAA-Na presented lower salt reversion than other. Moreover, the low RSF value due to the viscosity of PAA-Na is higher and molecular weight of PAA$\mathrm{Na}$ is lower than others.

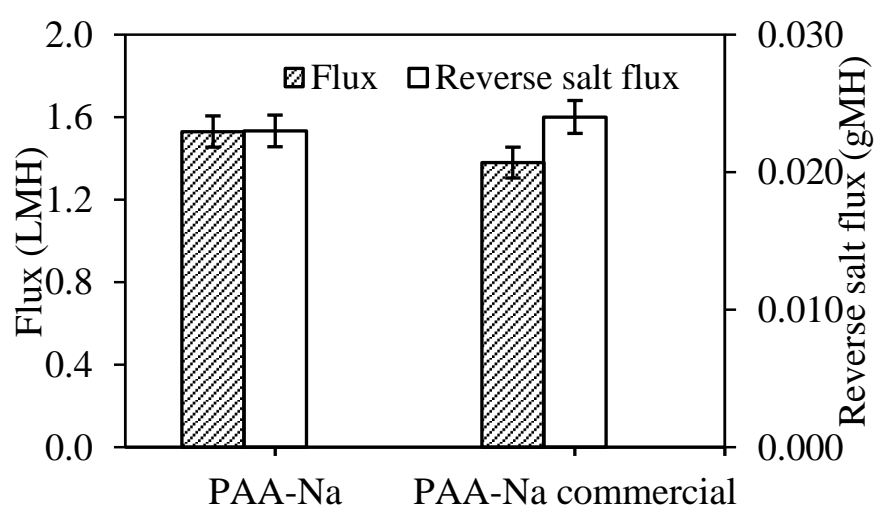

Figure 9 Water permeation flux and reverse solute flux of synthesis PAA-Na and Commercial PAA-Na

\subsubsection{Draw Solution Recovery Process}

Recovery process to achieve a constant concentration of draw solution by using Ultrafiltration system. The results was showed that the salt rejection were $54 \%$ and $21 \%$ for selfsynthesized PAA-Na and commercial PAA-Na, respectively. In addition, self-synthesized PAA-Na is higher salt rejection because of higher molecular weight than commercial PAA-Na [12].

\subsubsection{Stability of Synthesis PAA-Na}

Figure 10 shows the stability values of the flux after fed through the Ultrafiltration process. It was found that the flux was gradually decreased for each recycle number. The decrease was synchronized with the research of Zhao et al. [14] that maybe the stability of the polymer in solution was loss due to the decrease of mas of polyelectrolytes.

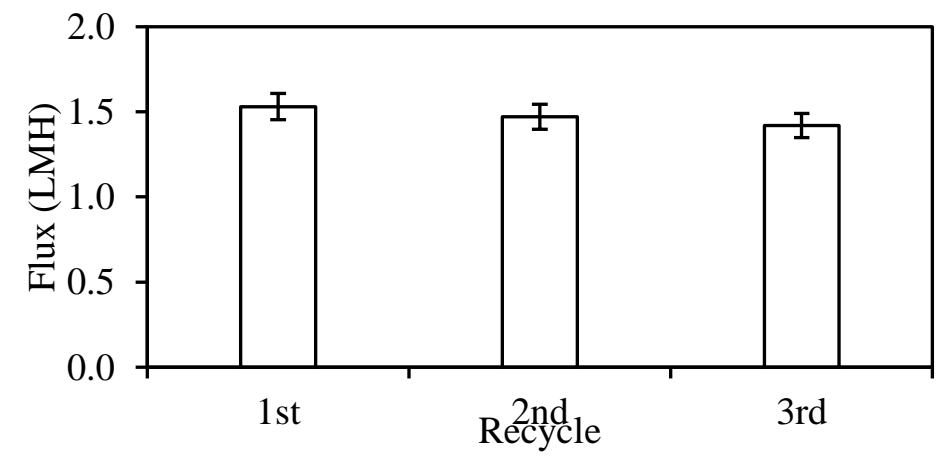

Figure 10 The recovery flux after filtrated by Ultrafiltration for each recycle 


\subsection{CONCLUSION}

The self-synthesized polyelectrolytes of PAA-K and PAA-Na showed the increasing of hydrophilic functional group like carboxyl $-\mathrm{OH}$ or $\mathrm{COOH}$. It was found that the lighter the molecular weight, the higher the osmolality and the greater the osmotic pressure. However, the molecular weight of PAA-Na was lower than PAA-K due to the different of the salt molecule compounds in salt polymerization. Self-synthesized polyelectrolytes obtained a small molecular weight and high osmotic pressure in the aqueous solution may exhibit a lower reverse solute flux in FO process. These result could be explained by the effect of the adding of the surfactant that presented hydrophobic interaction effect.

\section{ACKNOWLEDGEMENT}

The work was supported by the Government budget of Prince of Songkla University (ENG570900S). The authors are grateful thanks to all members of Membrane Science and Technology Research Center (MSTRC) for supporting.

\section{REFERENCES}

[1] W. Khongnakorn, W. Bootluck, and W. Youravong. 2014. Surface Modification of CTAFO Membrane by $\mathrm{CO}_{2}$ Plasma Treatment. Jurnal Teknologi. 70 (2): 71-75.

[2] B. Mi, and M. Elimelech. 2010. Organic Fouling of Forward Osmosis Membranes: Fouling Reversibility and Cleaning Without Chemical Reagents. J. Membr. Sci. 348: 337-345.
[3] T. Y. Cath., A. E. Childress, and M. Elimelech. 2006. Review: Forward Osmosis: Principles, Applications, and Recent Developments. J. Membr. Sci. 281: 70-87.

[4] Q. Ge, M. Ling, and T. S. Chung. 2013. Draw Solutions for Forward Osmosis Processes: Developments, Challenges, and Prospects for the Future. $J$. Membr. Sci. 442: 225-237.

[5] K. Y. Wang, M. M. Teoh, A. Nugroho, and T. S. Chung. 2011. Integrated Forward Osmosismembrane Distillation (FO-MD) Hybrid System for the Concentration Of Protein Solutions. Chem. Eng. Sci. 66: 2421-2430.

[6] M. M. Ling and T. S. Chung. 2011. Novel Dual-stage FO System for Sustainable Protein Enrichment Using Nanoparticles as Intermediate Draw Solutes. $J$. Membr. Sci. 372: 201-209.

[7] E. Tiana, C. Hu, Y. Qin, Y. Ren, X. Wang, X. Wang, P. Xiaoa, and X. Yang. 2015. A Study of Poly (sodium 4-styrenesulfonate) as Draw Solute in Forward Osmosis. Desalination. 360: 130-137.

[8] K. Lutchmiah, A. R. D. Verliefde, K. Roest, L. C. Rietveld, and E. R. Cornelissen. 2014. Forward Osmosis For Application In Wastewater Treatment: A Review. Wat. Res. 58: 179-197.

[9] A. Achilli, T. Y. Cath, and A. E. Childress. 2010. Selection of Inorganic-based Draw Solutions for Forward Osmosis Applications. J. Membr. Sci. 364: 233-241.

[10] H. T. Nguyen, N. C. Nguyen, S.S. Chen, H. H. Ngo, W. Guo, and C.W. Li. 2015. A New Class of Draw Solutions for 
Minimizing Reverse Salt Flux to Improve Forward Osmosis Desalination. Sci. Total. Environ. 538: 129-136.

[11] R. Kumar, S. Al-Haddad, M. AlRughaib, and M. Salman. 2016. Evaluation of Hydrolyzed Poly (isobutylene-alt-maleic anhydride) as a Polyelectrolyte Draw Solution for Forward Osmosis Desalination. Desalination. 394: 148-154.

[12] J. Huang, Q. Long, S. Xiong, L. Shen, and Y. Wang. 2017. Application of Poly (4styrenesulfonic Acid-co-maleic acid) Sodium Salt as Novel Draw Solute in Forward Osmosis for Dye-containing Wastewater Treatment. Desalination. In Press.

[13] S. Zao and L. Zou, 2011. Relating Solution
Physicochemical Properties to Internal Concentration Polarization in Forward Osmosis. J. Membr. Sci. 379 459-467.

[14] J. J. Kim, H. Kang, Y.-S. Choi, Y. Ah. Yua, and J.-C. Lee. 2016. Thermo-responsive Oligomeric poly(tetrabutyl-phosphonium styrenesulfonate)s as Draw Solutes for Forward Osmosis (FO) Applications. Desalination. 381. 84-94.

[15] D. Zhao, P. Wang, Q. Zhao, N. Chen and X. Lu. 2014. Thermo Responsive Copolymer-based Draw Solution for Seawater Desalination in a Combined Process of Forward Osmosis and Membrane Distillation. Desalination. 348: 26-32. 